\title{
E-LEARNING SCENARIOS USING INTELLIGENT MULTIAGENT SYSTEMS
}

\author{
Ali M. Aseere \\ College of Computer Science, King Khalid University,KSA \\ amg@kku.edu.sa
}

\begin{abstract}
Agent technologies could be a good approach to solving a number of problems concerned with personalised learning due to their inherent autonomy and independence. In this paper, we describe a number of e-learning scenarios that could be addressed by agent technologies. We then analyse these scenario highlighting how specific agent feature such as collation formation and bargaining (Negotiation) could be used to solve the problem. Our aim is to show how agent systems can not only form a good framework for distributed e-learning systems, but how well they match to situations where learners are themselves autonomous and independent.
\end{abstract}

\section{KEYWORDS}

Collation formation, personalised learning, Negotiation.

\section{INTRODUCTION}

E-learning systems have been used for a number of years in the delivery and management of learning content. More recently there has been a focus on how they could help personalize the learner's experience, as students begin moving from a world of VLEs (Virtual Learning Environments) into a space where students are taking more control of their learning in the form of PLEs (Personal Learning Environments).

Agent systems are a good approach to building systems where different people (represented by agents) may have orthogonal goals. As such they match very well with the world of personalized learning, where many students may have to negotiate with their peers, their tutors and their institution in order to achieve what they want within the constraints of other people's goals and objectives.

In this paper we present two scenarios showing the use of agent technologies in e-learning, the first is an independent student selecting a course, the second is personalized learning styles. We then analyses these scenario showing how specific agent features such as collation formation and bargaining (negotiation) might be used to solve that kind of problem

\section{RELATED WORK}

A number of researchers have applied agent technology to e-learning. Yang et al proposed to apply intelligent system to enhance navigation-training systems that consists of the client portion

David C. Wyld et al. (Eds) : CCSIT, SIPP, AISC, NLP - 2015

pp. 85-88, 2015. (C) CS \& IT-CSCP 2015

DOI : $10.5121 /$ csit.2015.50408 
and server portion using JADE framework [1]. However, they focus on the intelligence of the agents themselves, rather than communications between agents.

Shi et al. designed an agent system for computer science education that focuses on two courses where the learning process is student-centered, self-paced and highly interactive [2]. They use Java RMI, JavaSpace and JATLite to create a web-based system; in this case they use personal agents to manage student's data and their interactions with course material.

Agent technologies work well as a framework for building distributed systems, however it is only when some form of conversation, self-organisation or negotiation is needed that they become really valuable.

For example, Soh et al have shown a system called Intelligent Multiagent infrastructure for Distributed Systems in Education to support student in real time classroom where a buddy group is formed dynamically to support the members to achieve common goals [3].

In the next two sections we look at two scenarios that really utilize the potential of agent technologies, including a generalised version of this kind of group formation. In each case we provide a general description of the scenario, an analysis of the agent features within the scenario, and variations of the scenario that would also share the same features

\section{SCENARIO 1: COURSE SELECTION}

\subsection{Description}

Adult learners often act more independently than students straight out of school or college; they are also often enrolled in part-time courses where there is a lot of flexibility in how they receive credits. In these circumstances, the learners are free to choose which courses they wish to take, however the University is restricted on which courses it might run, due to the overheads of running each course.

Students therefore have to not only find courses which match their preferences, but also ensure that they enrol on courses in enough numbers to allow those courses to run. This might been compromising on their preferences, or changing their choices in the light of student numbers. In this kind of situation, the University is relatively passive, however it might help students reach agreement by suggesting courses that are likely to run.

\subsection{Agent Features}

In this scenario the students need to find other students with similar interests, and act together so that courses they are interested in will run. In Agent systems this is called a coalition formation problem, it occurs whenever agents are required to from groups in order to achieve some common goals [4].

Individual agents may need to compromise when joining a coalition, but the advantages of being inside a coalition outweigh the disadvantages, and may even be the only way for the agent to achieve their goals. In this case fulfilling the student's preferences becomes the goal for each student agent. 


\subsection{Variations}

This scenario is all about students making choices between alternatives, but where there are some external restrictions on those choices that might make it useful to act together. As way as making module choices this would also be relevant for students choosing a course, or even making choices between Universities. In this last case the factors might also include issues such as reputation, distance from home, facilities and so forth.

\section{SCENARIO 2: PERSONALIZED LEARNING STYLES}

\subsection{Description}

Different student may have different personal preferences about the way they want to learn or be assessed. For example, students may have a preferred learning style (for example, some students may prefer information presented visually). However, an institution may have regulations about having a mixed set of assessment styles. For example, many Universities are cautious about having modules assessed by $100 \%$ course work.

This can cause conflict, as the student wants to be assessed in the way they prefer the most. In these cases there is a need for the student to negotiate with their teacher about the methods of learning or assessment that will be used.

\subsection{Agent Features}

In this scenario there is an institution that associates a cost with each type of learning or assessment and wants to minimize that cost (or at least prevent it from rising above an agreed level). This cost need not be financial, and could include factors such as value to external assessors, or complexity for staff to manages.

For each student we can define a utility function that calculates their satisfaction with the styles they have been allocated. Students can now bargain (negotiate) with their institution, exchanging items according to their cost until their utility function is maximized within the constraints of the institution's cost level

\subsection{Variations}

This scenario could also be applied to students with learning differences, such as dyslexia, in which case they could have different requirements about how they are assessed (for example, preferring project work to exams). An institution might apply different rules to these students, but could use the same economic framework to negotiate their assessment.

\section{SUMMARY OF AGENT TECHNIQUES}

In the scenarios presented above, we have found that agent technologies, which are based on economic models, such as coalition formation and bargaining can be applied in an e-learning setting.

Coalitions of agents are temporary groups that exist to solve a particular problem. There are generally two different approaches to solving the coalition formation problem. With the centralized approach a single agent (for example, the institution) gathers all the data and makes a decision[5]. It has the advantage of being simpler to manage, but doesn't really take advantage of 
agent autonomy. With the decentralised approach the problem is solved by a number of different agents working together [6]. A decentralised approach could allow students to form their own coalitions independently (e.g., in Scenario 1 by negotiating amongst themselves about a strategy for course registration to maximize their satisfaction as a whole).

Bargaining (negotiation) is a technique for reaching agreements in a multi-agent system. Any negotiation setting will have four different components [7]:

- A negotiation set, which represents the space of possible proposals that agents can make.

- A protocol of the legal proposals agents can make.

- A collection of strategies (the strategy that each agent plays is private)

- A rule that determines when a deal is struck and what the agreement is.

In Scenario 2 the institution and students have a conflict of interest. Bargaining is used to resolve conflicts, and achieve agreement between them

\section{CONCLUSION}

In this paper we have argued that agent technologies could be a good match for personalized elearning. We have presented two scenarios showing the use of agent technology in e-learning and identified a number of agent techniques that could be used to solve the challenges in each scenario: coalition formation and economic systems based on bargaining (negotiation).

We plan to continue this work by building a number of prototype agent systems in the JADE agent framework, and exploring whether existing e-learning standards and models of student preferences are sufficient to support an agent-based solution

\section{REFERENCES}

[1] Yang, C., Lin, H. and Lin, F. O. Designing Multiagent-Based Education Systems for Navigation Training. 5th IEEE Int. Conf. on Cognitive Informatics (ICCI'06)2006).

[2] Shi, H., Shang, Y. and Chen, S.-S. A multi-agent system for computer science education. SIGCSE Bull., 32, 3 2000), 1-4.

[3] Soh, L.-K., Jiang, H. and Ansorge, C. Agent-based cooperative learning: a proof-of-concept experiment. SIGCSE Bull., 36, 1 2004), 368-372.

[4] Horling, B. and Lesser, V. A survey of multi-agent organizational paradigms. Knowl. Eng. Rev., 19, 4 2004), 281-316.

[5] Aknine, S. A reliable algorithm for multi-agent coalition formation. IEEE1999).

[6] Shehory, O. and Kraus, S. Methods for task allocation via agent coalition formation. Artificial Intelligence, 101, 1-2 1998), 165-200.

[7] Wooldridge, M. An Introduction to Multiagent Systems Wiley \& Sons, Chichester, England 2002. 